\title{
Filmgeschichten
}

\author{
Erhard Taverna
}

Durch das kahle Geäst vom anderen Ufer bescheint die Morgensonne den Fluss. Ein Schwan überquert mit schweren Flügelschlägen die grün aufleuchtenden Strudel der starken Strömung. Schon um diese Zeit ist das Café an der Aare im «Haus am Land» gut besetzt. Das 39. Filmfestival in Solothurn wird jedes Jahr besser besucht, die Leute stehen vor der Auskunft Schlange, verstauen das Infomaterial in den gestapelten Tragtaschen und warten abends geduldig an der Kasse.

\section{Die Hintergründe}

Jährlich kommt das Publikum in Scharen nach Neuchâtel, Locarno, Baden, Les Diablerets, Genf, Basel, Winterthur, Bellinzona, Lausanne, Fribourg und Nyon. Unter diesen Festivals hat es Neulinge und Veteranen, Spezialisten für das fantastische Kino, für Amateure, Animation, Trickfilme, Dokumentation, Sport, neue Medien, Kurzfilme, Autoren, Technik und Energie, Jugendliche, schweizerische und ausländische Produktionen. Alle brauchen Sponsoren, amtliche Fördergelder, alle haben eine Jury und vergeben Preise. 23 Hersteller produzieren hierzulande Filme, die über rund $30 \mathrm{im}$ Land domizilierte Verleihgesellschaften, in die Kinosäle und auf die TV-Kanäle gelangen. Mit fast 20 Millionen Kinobesuchern ist die Schweiz eine Konsumentengrossmacht. Keine europäische Grossstadt bietet ein derart reichhaltiges Kinoprogramm wie Zürich. Doch hier in Solothurn, wo die eigene Produktion im Mittelpunkt steht, folgt gleich die Ernüchterung, denn die im Jahr 2002 hergestellten 37 Filme kommen gerade mal auf einen Anteil von 3,7\% aller Aufführungen. Immer noch einsam an der Spitze liegen die «Schweizermacher» von Rolf Lyssy (1978) und weit abgeschlagen auf Platz zwei «Les Petites Fugues» von Yves Yersin (1979). Vielleicht werden «Achtung, fertig, Charlie» oder «Ernstfall in Havanna» die Rangliste neu aufmischen. Besucherzahlen von über einer Million wie bei «Titanic» oder «Harry Potter» bleiben Wunschträume. Die Juroren von Solothurn hoffen, dass die gekürten Publikumsrenner, ähnlich wie in Holland, Norwegen oder Dänemark, den Marktanteil für alle Inländer zumindest verbessern.
Das kleine Land wird durch seine Sprachregionen, den Kantönligeist, oft mangelnde Professionalität und eine fehlende Filmhochschule zusätzlich behindert. Zum jährlichen Ritual gerät der Ruf nach mehr Geld, mehr Förderung und einer stärkeren Zentralisierung. Eine Initiative wie «Swiss Films» von der Kulturstiftung Pro Helvetia, des Schweizerischen Filmzentrums und der Kurzfilmagentur Schweiz hat sich eine bessere Promotion und Imageförderung zum Ziel gesetzt.

\section{Das Programm}

Nebst neuen, spannenden Spielfilmen wie zum Beispiel «Hildes Reise» von Christof Vorster bestechen die vielen guten Dokumentarfilme. Allein der Jahreskatalog 2003 von «Swiss Films» (www.swissfilms.ch) listet 33 Kinofilme und 14 TV-Filme auf. Einige mehr erreichen in Solothurn erstmals ihr Publikum, darunter auffallend viele, die thematisch auch den medizinischen Alltag betreffen. Der längere Film «früher oder später» von Jürg Neuenschwander etwa, der Sterbende und Trauernde im Spital und zu Hause einfühlsam begleitet. Bilder und Momente auf dem Weg in den Tod, unsichtbare Gesten und Regungen, die Schmerzen des Abschieds, die Rituale, die Unsicherheit, die Angst, die Scham, die unentrinnbare Vergänglichkeit. Oder der ebensolange Dokumentarfilm «Halleluja! Der Herr ist verrückt» von Alfredo Knuchel, der, ausgehend von der Sammlung des Psychiaters Walter Morgenthaler, sechs Menschen bei ihrer kreativen Arbeit vorstellt. Oder kürzere, nicht weniger eindrucksvolle Porträtfilme wie «Stephan@Nadelöhr.Zürich» von Gaby Schädler: Selbstreflexionen eines Ex-Junkies, seine Angst vor der Normalität, Rückblicke auf den Platzspitz 1991, die Wärme und Geborgenheit der Gruppe, der Absturz als Programm, das Heroin als Ziel der Sehnsucht. Die Angst vor der Auseinandersetzung mit sich selbst, eindrückliche, intime Bilder ohne jeden Voyeurismus. Nicht nur die Dokumentation einer Drogenkarriere, sondern vielmehr ein Bericht über das Leiden an der Banalität des Daseins und den Schwierigkeiten, das Leben anzunehmen, so gewöhnlich wie es ist. Oder «Frauen mit HIV» von Paul Riniker. 
Aufwühlende und ergreifende Porträts von fünf Frauen, die sich hoffend und verzweifelnd mit ihrem grausamen Schicksal auseinandersetzen. Ein trotz aller Tränen und Verletzungen wunderschöner Bericht, der auch sehr viel Kraft und Mut vermittelt. Zwei Filme, die sich auch sehr gut in der Präventionsarbeit verwenden liessen.

Der Dokumentarfilm ist zum Markenzeichen der Schweiz geworden. Kaum woanders gehen die Leute wegen eines Dokumentarfilms ins Kino. Im Vergleich zum Spielfilm ist er drei- bis viermal billiger und finanziell einträglich, wenn er wie mit Mani Matter oder Elisabeth Kübler-
Ross im In- und Ausland Erfolg hat. Vielleicht kompensiert er besser die fehlenden Stars und die Sprachbarriere der Dialekte, die sich für den Alltag besser als für die grossen Drehbücher eignen.

Dissonanzen sind nur am Rande zu vermelden: Der einheimische Fasnächtler, der sich über die «Filmfritzen» geärgert hat, weil sie sich nicht für seine «Plaketten» interessierten. Und die behinderten Festivalbesucher, deren verständliche Wünsche nach Platzreservierungen an der hilflos-netten Inkompetenz der Veranstalter scheiterten. 